\title{
PENSAR OS AUTORRETRATOS DE VIVIAN MAIER THINK ON VIVIAN MAIER'S SELF-PORTRAIT
}

\author{
Profa. Dra. Márcia Rodrigues da Costa \\ Universidade de Sorocaba \\ marciarcosta13@gmail.com \\ Prof. Dr. Rodrigo Fontanari \\ Universidade de Sorocaba (Uniso) \\ rodrigo-fontanari@hotmail.com
}

\begin{abstract}
Resumo: Este artigo analisa alguns autorretratos de Vivian Maier enquanto construção de cena, espécie de ficção, recorrendo a Barthes, e ao conceito de mise en abyme, conforme o escritor francês André Gide. Em seus autorretratos produzidos com o espelho, a presença da fotógrafa é quase sempre posta em cena desdobrada, rebatida em perspectivas múltiplas, conduzindo-nos a questionar a própria condição do autorretrato, da imagem de si para si mesmo e para o olho do outro. Estas imagens nos mostram a mise en abyme, possibilitada pelo jogo de espelho ou de espelhamento que Vivian Maier explora.
\end{abstract}

Palavras-chave: Vivian Maier; Autorretrato; Imagem.

Abstract: This article analyzes some self-portraits of Vivian Maier while construction of scene, species of fiction, appealing to Barthes, and to the concept of mise en abyme, according to the French writer André Gide. In her self-portraits produced with the mirror, the photographer's presence is almost always posed in an unfolded scene, rebuffed in multiple perspectives, leading us to question the very condition of self-portrait, self-image for oneself and the other's eye. These images show us the mise en abyme, made possible by the mirror or mirror game that Vivian Maier explores.

Key words: Vivian Maier; Self-portrait; Image

Vivian Maier viveu durante quarenta anos nos Estados Unidos atuando como babá profissional e fotógrafa até os seus últimos dias de vida, e só há alguns anos ficou conhecida no mundo todo como a babá fotógrafa que registrava imagens de forma catártica, espontânea e sensível. No Brasil sua obra foi mais difundida principalmente após o lançamento do livro Vivian Maier: uma fotógrafa de rua (MALOOF, 2014), que revela imagens que ela produziu em Chicago e Nova York ao longo dos anos 1950.

A pesquisa histórica realizada sobre sua vida-obra mostra que a fotógrafa nata nunca estudou em escolas de fotografia, tendo produzido mais de 100 mil imagens entre 1950 e 1990, em diversos países, principalmente nos EUA. Seu trabalho por trás das lentes ficou conhecido após 50 anos de muito segredo sobre o ofício de fotógrafa, quando o historiador John Maloof comprou os negativos de Maier em uma casa de leilão em 2007, na cidade de Chicago (EUA). A partir daí, ela, que sempre teve a vida reservada, passou a revelar-se por meio de sua fotografia. Sua obra, como se sabe, 
ganhou notoriedade mundial por conta da ampla difusão realizada por Maloof por meio de exposições, livros e um documentário sobre a fotografia de Vivian Maier.

Quem conviveu com ela — principalmente aqueles que a contrataram como babá - testemunham que ela era considerada como uma pessoa "excêntrica", reservada, misteriosa e dotada de grande talento para a fotografia e de uma vida extremamente privada. Até onde se sabe, ela nunca se casou, não teve filhos nem nutriu muitas amizades. Em sua obra percebem-se pistas de sua personalidade e identidade. "[...] alguém que existe unicamente nas coisas que viu", escreve o escritor britânico Geoff Dyer, no prefácio do livro que Maloof editou sobre a fotógrafa (MALOOF, 2014, p. 8).

Suas imagens fotográficas revelam um apurado senso estético, uma "sensibilidade elegantemente adaptada" que se tornava visível por meio de "suas roupas, o recorrente chapéu de abas longas e flexíveis e o casaco" por elas utilizados ao circular "discretamente pelas ruas de Chicago e Nova York" (p. 9), assinala Dyer. Vivian Maier se fotografava basicamente de duas formas: em ambientes internos (até mesmo em banheiros privados ou públicos, por exemplo); e outras tantas vezes nas ruas de Chicago e Nova York, em diálogo com o movimento urbano, inserida em uma "modalidade visual que expressasse a vida moderna, sua mudança, velocidade e alienação resultante" (LEDERMAN, 2012, p. 289).

Há quem trabalhe com a ideia — como é o caso de Geoff Dyer — de que muitas das fotos de Vivian Maier se assemelham ao do trabalho de outros fotógrafos cuja obra é bastante conhecida e acolhida pela crítica, como Lisette Model, Helen Levitt, Diane Arbus, André Kertész, Walker Evans, o que nos leva a crer que o olhar de Maier é significativamente influenciado pelo "ar de seu tempo", ou ainda pela visualidade da época. Não se sabe, no entanto, se ela teria conhecimento do trabalho destes profissionais ou teria se inspirado em composições de revistas ou exposições.

Dentre os nomes da fotografia moderna e para além dos já mencionados, é preciso lembrar, quando se pretende entender um pouco mais o processo de construção da imagem de Vivian Maier, do fotógrafo Lee Friedlander, que como Maier, atuava na cena urbana, e cujas fotos propiciavam "um comentário sobre o processo de produção fotográfica e o ato de se observar" (HIGGINS, 2012, p. 368). Ambos, como se sabe, tinham o hábito de incluir sua sombra ou reflexo nas cenas que fotografavam, mas 
diferente de Vivian, Friedlander não mostrava seu rosto à câmera, ele o ocultava por meio de objetos (p. 369-370).

Além disso, as fotografias urbanas de Vivian destacam a complexidade e o cotidiano da vida norte-americana, tal qual fazia Friedlander em meados dos anos 1960, representando a cidade contemporânea. As imagens de Vivian comunicam sobre a modernidade, unindo humor, imaginação, criatividade e suspense em diversas camadas de significados imagéticos. A importância das suas fotografias de rua se dá principalmente também por conta da memória histórica que carregam, já que elas são registro de um tempo do qual hoje só se tem acesso por meio de imagens.

Ora, essa aproximação entre Vivian e o trabalho de um grande fotógrafo mostra, de alguma maneira, que as imagens produzidas por eles não se traduzem em mera presença ou em uma exposição do ego típica das selfies, mas em um realce da psique e da história por trás de seus autores. Em 40 anos de fotografia de rua, Maier produziu muitos autorretratos, tanto em ambientes internos (meio privado) quanto externos (meio público). Por meio de sua produção ela parece ter construído sua autobiografia em imagens.

Os autorretratos de Vivian Maier revelam muito de sua obra, a começar pela escolha do tipo de câmera Rolleiflex pendurada no colo, o que permitia à fotógrafa-babá lançar mão do disparo na rua, a qualquer momento discretamente, como se o que contasse fosse o instante capturado e não o gesto fotográfico para a sua captura. Em ambientes internos, outro recurso utilizado por ela para produzir autorretratos era também o uso do tripé.

Vivian buscava se projetar (visto que é para seu reflexo que sua objetiva se volta) na cena urbana, colocando-se ao lado dos personagens que compõem o cotidiano da cidade, ou se fotografar sozinha. Assim, relacionava-se com a cidade e se fotografava por meio de espelhos e vitrines, além de utilizar o recurso da sombra. Já em ambientes privados ela se registrava só na cena, o que revela um tipo de trabalho realizado de forma mais privada e praticamente isolada.

O gesto de se autofotografar é de certa maneira uma prática muito comum entre fotógrafos, haja vista a própria história da fotografia. São inúmeros os profissionais que, em algum momento, voltam a objetiva para si ou contra si mesmo. O autorretrato fotográfico consiste em uma imagem que articula num mesmo espaço cênico o objeto e o fotógrafo, ou para dizermos como Philippe Dubois (2006, p. 156), "é o único retrato que reflete um criador no próprio momento do ato de criação". O ver sendo visto ou 
fotografar-se fotografando realiza-se perfeitamente nos autorretratos de Vivian Maier na medida em que, consciente ou inconscientemente, ela lança mão de uma técnica historicamente bastante utilizada na pintura e na gravura, que se denomina mise en abyme, termo que retomaremos logo adiante.

O escritor argentino Alberto Manguel (2001, p. 197), em Lendo imagens, ao se enveredar pela questão da imagem como reflexo, nos ensina, amparado pela introdução do crítico Ernst van de Wetering ao catálogo da exposição de 1999 intitulada Rembrandt por ele mesmo, que o termo autorretrato, para se referir a essa fabricação de imagens de si, surgiu apenas a partir do século XIX. Anteriormente, para exprimir essa forma de representação, diríamos, "a imagem de Rembrandt feita por ele mesmo ou retrato de Rembrandt pintado por ele mesmo". A palavra autorretrato torna-se vernácula no Oxford English Dictionary a partir de 1840, enquanto sua primeira ocorrência encontra-se em Miscellanies of Literature de Issac D'Isareli. Ora, o que tudo isso parece sinalizar é que, nesse "pensamento primitivo", de um lado, há uma cisão entre o observador (pintor) e o observado (tema), e, de outro, não há o que o que denominamos de autorretrato, visto que "aquilo que o pintor vê e reproduz sobre a tela está fora do pintor, é 'um outro"” (2001, p. 197).

É nesse ponto que a descrição dramática da experiência de Roland Barthes em $A$ Câmara é válida para pensar o quanto nos transformamos em outro diante da objetiva. A construção da cena (com a presença do fotógrafo inserido nela) e o próprio gesto de posar face à câmera é um traço forte no trabalho de Vivian Maier. Diante da câmera ela se constrói, fabrica um "eu" de si que é pura imagem para a objetiva. Lemos na derradeira obra em vida de Barthes seu testemunho sobre isso: "a partir do momento que me sinto olhado pela objetiva, tudo muda: ponho-me a posar, fabrico-me instantaneamente outro corpo, metamorfoseio-me antecipadamente em imagem", (2015, p.18).

Se por um lado o retrato é interpretado como um espelho, o espectador se torna para este tipo de imagem outro espelho para a própria imagem, confundindo e misturando os papéis entre observador e observado. Por outro lado, o autorretrato, nas experimentações estéticas de Vivian Maier, ao colocar para dentro da cena a figura do espelho e, junto com ele, seu reflexo, quebra essa força de apossamento da imagem e pela imagem, abrindo-a ao fragmento, à dispersão, em que o próprio espelho já não é nem um objeto por duplicação que mostra as qualidades vistas na realidade sólida do mundo da carne, nem dá a ver o mundo interior da alma. O que se vê é de fato sempre 
"um outro", sua sombra, seu reflexo: aquilo que de si se projeta sobre a superfície espalhada.

De resto, ao fotografar insistentemente seu reflexo numa superfície refletora como espelho, por exemplo, buscando pelo seu “ser", Vivian Maier não está distante do mesmo engodo que ocorre em Narciso ao acreditar que seu reflexo é uma pessoa real. Ou então se sua fascinação por se autorretratar revela esse desejo de conseguir ver quem era, ela não está distante do mesmo movimento en plongé sobre certas fotos que organiza toda reflexão de Roland Barthes em A câmara clara. Afinal, o semiólogo busca, naqueles 48 fragmentos, encontrar a "verdade do ser" em sua imagem. Como interpreta Françoise Gaillard, filósofa e maître de cofénrences em literatura francesa da Universidade de Paris VII, em seu ensaio intitulado "J'ai toujours une mauvais rapport à mon image" há, em A câmara clara, uma gradação em três níveis. Uma primeira gradação refere-se à "fotografia conforme: aquela que só restitui das pessoas sua identidade". Numa segunda, encontra-se a "fotografia semelhante", em que a imagem fotográfica captura muito além "dos traços", leva consigo também "a expressão individual". E, por último, a "fotografia justa", aquela que "alcança a verdade do sujeito por ter sabido exprimir 'o ar"” (1992, p. 60).

Em seus autorretratos, até mesmo por conta da entrada em cena do próprio espelho, a presença da fotógrafa é quase sempre posta em cena desdobrada, rebatida em perspectivas múltiplas, conduzindo-nos a questionar a própria condição do autorretrato, da imagem de si para si mesmo e para o olho do outro. O que boa parte desses autorretratos nos mostra é a mise en abyme, possibilitada pelo jogo de espelho ou de espelhamento que Vivian Maier explora nos espaços públicos e privados.

O procedimento mise en abyme no processo fotográfico de Maier não redobra a imagem, como se de um reflexo externo consistisse, mas enquanto espelhamento interno, que desdobra a imagem, esfacelando-a em múltiplos fragmentos. Causa uma certa interrogação quando se nota sua presença num autorretrato. $O$ que afinal quer sugerir Maier ao se colocar em abismo em meio às estruturas do cenário escolhido?

Talvez a resposta para tudo isso esteja na própria definição de mise en abyme. Cunhada primeiramente pelo escritor francês André Gide, em 1893, de uma maneira bastante precisa, para se referir ao fragmento de um texto capaz de reproduzir, tal qual uma miniatura, o texto em sua completude, em sua inteireza. São, no entanto, como se sabe, os nouveaux romanciers, nos anos de 1950, que elegeram a mise en abyme como sua técnica narrativa predileta. Trata-se de um tipo de construção em abismo, de 
duplicação interna dentro da própria obra, seja ela textual ou imagética, frequentemente, associada ao espelho e a ele confundido. O jogo de espelhamento interno à imagem faz vacilar sua estabilidade, na medida em que ela se mostra interpolada por outros reflexos vindo de alhures. Tanto é que, para Lucien Dällenbach, em Le récit spéculaire, a mis en abyme é "todo espelho interno refletindo o conjunto do relato pela reduplicação simples, repetida e especiosa" (1977, p. 52). É, aliás, o próprio Gide que assinala analogicamente a aproximação da mise en abyme ao fotógrafo de autorretrato que, diante do espelho, põe a fotografar se fotografando.

O que de fato define a mise en abyme é qualquer aspecto dentro de uma obra que espelhe a grande obra que a contém. Uma obra dentro da obra; meio pelo qual a obra se volta para si mesmo (como reflexo). Rejeitando a noção de simples duplicação exata (de reflexo fiel), o efeito da mise en abyme não consiste em simplesmente duplicar, como podemos acreditar de saída - ela desdobra. É um erro compreender o termo mise en abyme com um equivalente a um mero mimetismo, pois sua função não é a de fabricar um duplo. A ilusão óptica procurada é a de trazer à imagem coisas que estão fora dela. Reflexos dados pelos espelhos complementam a imagem e funcionam primeiro como um médium de inter-troca, abolindo a oposição entre dentro e fora.

Ao colocar o sujeito fotografado em abismo, a imagem refletida no espelho coloca também, evidentemente, a representação fotográfica em abismo enquanto representação interiorizada de seu próprio processo de fabricação. A mise en abyme mostra que as fotografias são elas mesmas imagens virtuais que apenas remetem a imagens de um mundo real, obrigando assim o espectador a reconhecer a "virtualidade' desses personagens refletidos, o que transforma a superfície da fotografia em um campo de representação capaz de representar seu próprio procedimento de representação.

Em comum, esses autorretratos têm a renúncia a qualquer suposição da inteireza das imagens, qualquer flerte com o instante absoluto de qualquer prise de vue. Efetivamente, há que se sublinhar seu caráter parcial, fragmentário, lacunar, vertiginoso, que é próprio do modelo estético da mise en abyme. Em nenhum dos casos, o real se entrega por inteiro. Aí está a punjança das imagens de Vivian Maier. Seus autorretratatos, contrariamente ao que se espera, não conduzem o espectador plenamente nem ao seu mundo interior, nem mesmo deixam materializar por completo o seu entorno.

O espectador não consegue, como num retrato, a mesma investidura em direção do olhar do retratado que o faz confundir (ver se vendo); ele aí, pelo contrário, se perde 
na vertigem do mosaico de imagem, instaurando uma crise na própria concepção realista a que a imagem fotográfica é remetida.

\section{Figura 1}

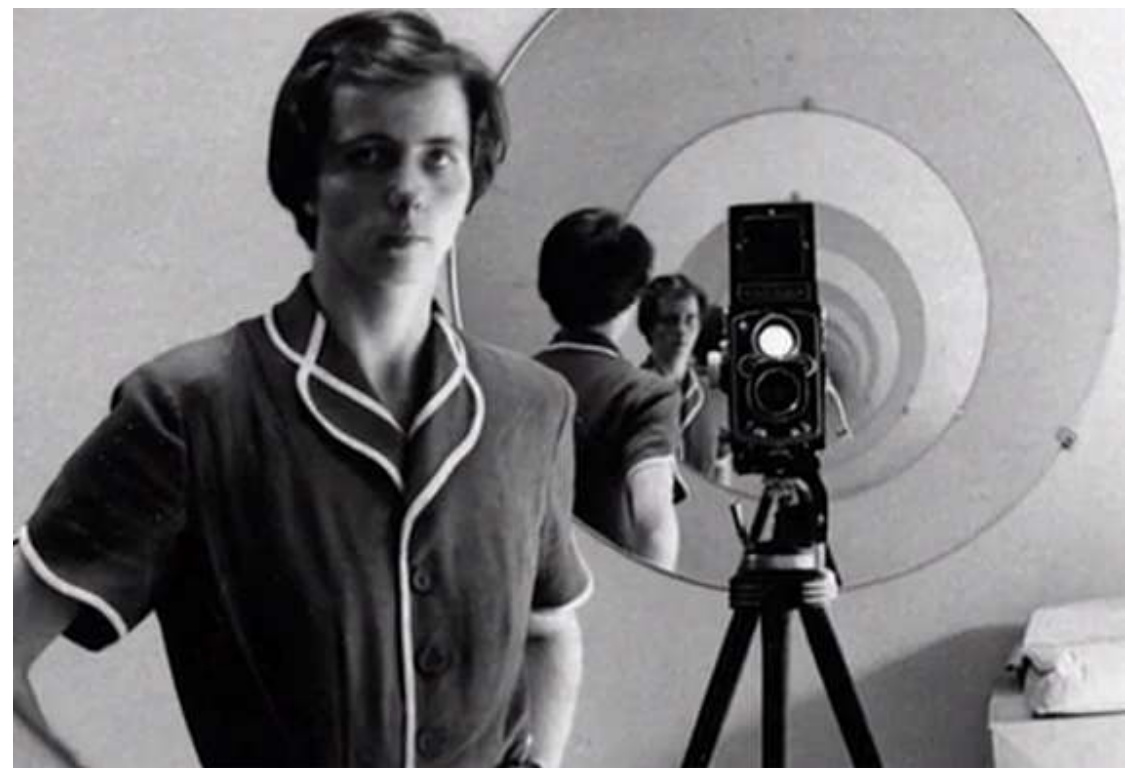

Fonte - Site oficial sobre Vivian Maier. Disponível em:

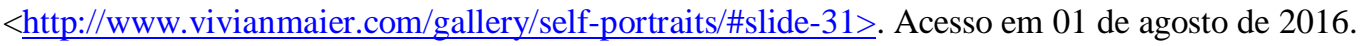

$\mathrm{Na}$ imagem acima Vivian Maier surge em primeiro plano, de frente para o espectador e para o espelho. Uma outra Vivian, em proporção menor, está de costas, seguida por outra de frente, e assim sua imagem se apresenta ao espectador de frente e de costas, sucessivamente. É como se fosse uma imagem dentro de uma imagem, um espelho dentro de outro espelho. Como a câmera fotográfica está posicionada de frente para o espelho, não há, na sua imagem, uma referência de objeto, já que o espelho apreende sua sombra, que se abre em um abismo, em um vórtice do infinito, e, ao se abrirem, essas imagens se fragmentam em pedaços menores.

Vestida com roupa de babá e de posse da câmera fotográfica, ela mistura seus personagens, apresentando seus múltiplos eu, o seu reflexo, ampliando-se da representação para o objeto, indo ao infinito. Por meio de um jogo de espelhos, suas imagens se multiplicam, expondo um dentro-fora infinitamente.

Ao contrário dos espelhos, o autorretrato reflete outra (s) Vivian (s), formando verdadeira imagem caleidoscópica no entrecruzamento dessas encenações. O olhar do espectador não consegue apreender a babá ou a fotógrafa, pois o que existe não é uma ou outra, mas a babá e a fotógrafa. Ou seja, não se trata de uma coisa e outra, mas de 
adições de múltiplos eus, como se ela dissesse: "eu me afirmo como tal, como fotógrafa e como babá".

O gesto fotográfico de voltar a objetiva para si como um dedo indicador que aponta, desafia, tudo isso pede para ser remetido metaforicamente ao mito da Medusa, como sinaliza Philippe Dubois em $O$ Ato fotográfico. Pois, para ele, a imagem, o autorretrato ou a fotografia de si funda-se nos mesmos temores e medos históricos suscitados pela cabeça de Medusa, na medida em que a fotografia é aí "pega na vertigem do nó que a amarra e do buraco que a afasta” (2006, p. 147). Ora, se o autorretrato se caracteriza por esse estranho movimento de amarração e afastamento, é porque o fazer fotográfico (ao menos é o que nos faz acreditar Dubois) se faz no instante que está se produzindo, em que ainda não se é totalmente imagem petrificada (foto), mas que já se tornou máscara (pose) ao ter a objetiva inteiramente apontada para si.

\section{No jogo de espelhos, imagens que se multiplicam}

\section{Figura 2}

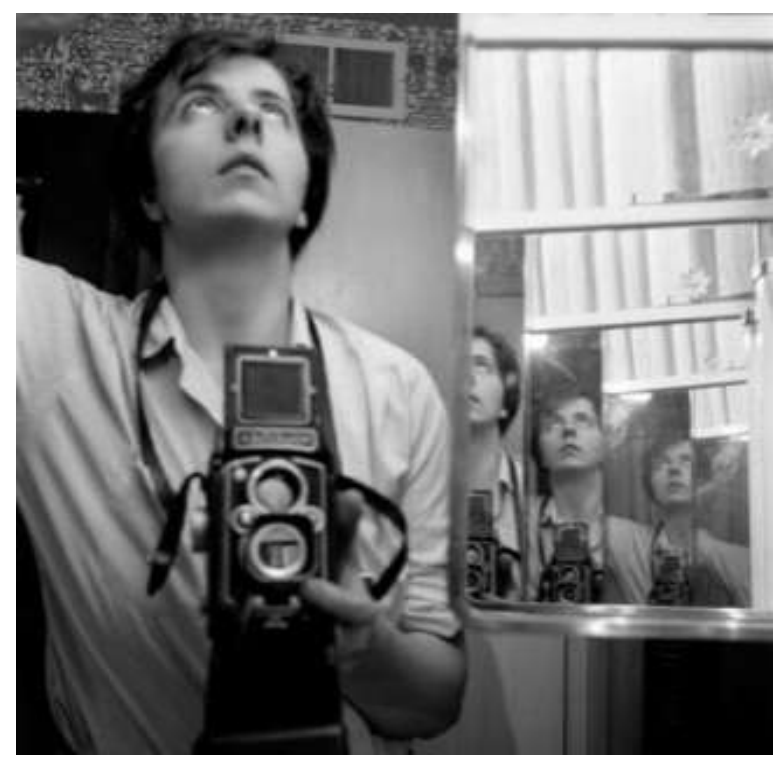

Fonte - Site oficial sobre Vivian Maier. Disponível em: http://www.vivianmaier.com/gallery/selfportraits/\#slide-33 Acesso em 01 de agosto de 2016. 
Figura 3

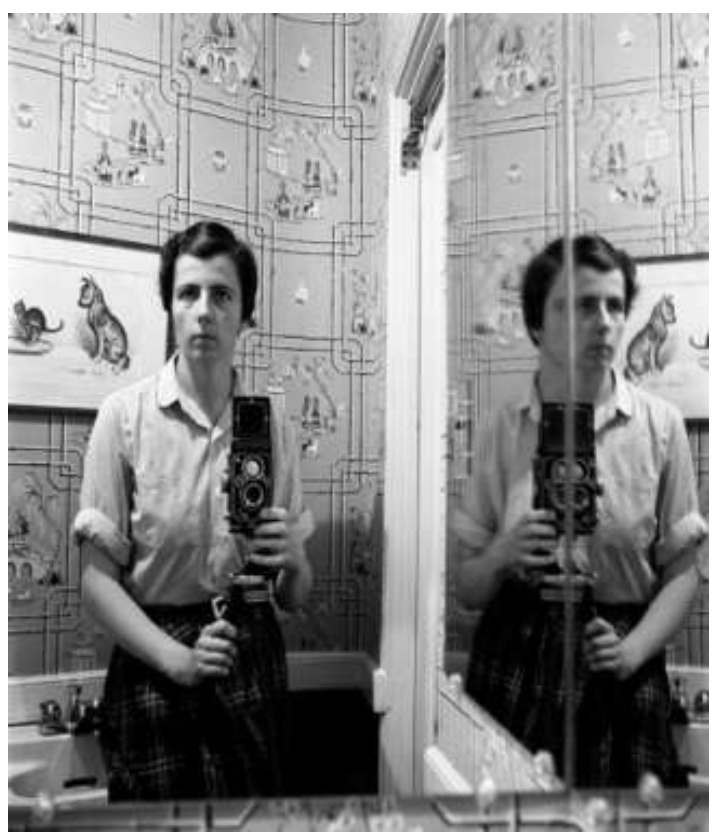

Fonte - Site oficial sobre Vivian Maier. Disponível em:

http://www.vivianmaier.com/gallery/self-portraits/\#slide-32 Acesso em 01 de agosto de 2016.

Nas duas imagens acima, como na anterior, Vivian Maier nos leva a pensar sobre ela e sobre o próprio fazer do autorretrato. As três imagens nos trazem referências da fotógrafa como uma questionadora do valor de referência do real. Barthes, ao ver a fotografia para além do seu mero "efeito de real", buscava nas imagens uma forma de pensar o mundo, ou seja, ele vê a imagem como algo que está para além do que ela representa, já que a imagem tem o potencial de criar um texto em torno dela, de gerar reflexão, de despertar nosso afeto, provocando nosso pensamento e imaginário.

$\mathrm{O}$ autorretrato é elemento fundamental nesse questionamento do real, uma espécie de espelho de Vivian Maier, onde ela se projeta e reflete a imagem de um ou mais personagens criado por ela. Suas imagens suscitam os embates entre a representação e seus limites, entre o óbvio e o obtuso, termos cunhados por Barthes (ano). Ou seja, não existe referente, nunca estamos diante dela, do seu corpo, já que o espelho se coloca entre ela a objetiva. Ela sempre se dá na sombra, no abismo, no fragmento. Seu autorretrato capta, assim, o seu reflexo e não o seu corpo ou o seu "eu".

Quando a fotógrafa questiona a própria fotografia e o seu referente, ela mostra que o objeto pode estar diluído na sua própria representação. O índice, da mesma forma, também está diluído, perde conexão com o objeto, já que Vivian Maier não se deixa 
apreender no autorretrato. Como no Surrealismo, esse tipo de imagem não se ancora na realidade, que se desfaz.

Ao romper com o figurativo e representar-se enquanto linguagem fotográfica propriamente dita, Vivian, de forma criativa e lúdica, constrói seu retrato colocando-se em cena, em uma autorreferência, mostrando em cada fotografia partes de si que apontam para sua obra. Suas duas personas ou personagens, a babá e a fotógrafa que permeiam a cena, não chegam a se fixar para nós enquanto identidades estanques, já que a sua fotografia é caracterizada como um espaço de encenação, espaço discursivo híbrido e ambivalente de intersecção entre vida e obra.

A imagem que ela projeta no reflexo consiste em um fragmento que tem uma relação de semelhança com a sua obra. Ou seja, a imagem especular do espelho manifesta e evidencia a estrutura que a compõe, uma das propriedades da mise en abyme. Diante do reflexo seus autorretratos revelam uma reduplicação, partes fundamentais de um todo, que é sua obra. Eles trabalham a distância entre o seu eu e o outro por ela projetado ou representado.

Em sua imagem produzida ela é ao mesmo tempo sujeito e objeto da ação, já que se torna o próprio objeto de representação. E como o autorretrato reflete o criador no momento da criação, ao encenar-se ela fotografa fotografando-se, o que torna impossível a figuração real dessa representação e a condensação destas duas instâncias, condição fundadora do autorretrato.

Ao realizar seus autorretratos por meio do uso do espelho (ou outra superfície refletora, como as vitrines das lojas), a fotografia da sua própria sombra, o uso do disparador automático ou de efeito retardado, entre outras estratégias de apreensão da autoimagem, Vivian Maier exerce um gesto de perder-se em si mesma, brincando com suas identidades. Seus autorretratos fazem emergir a imagem de um outro que não é mais ela, é o resultado do gesto que se concretiza na encenação. As imagens produzidas por ela não congelam a imagem da babá ou fotógrafa, mas brincam com um outro, que é a tradução das duas.

Os jogos dos autorretratos, como nos espelhos, apresentam uma busca e uma presença constante de um ser outro (s) e do duplo. Vivian Maier usa sua própria imagem como material para mergulhar nos retratos ou espelhos no seu interior, no seu dentro: ela os reduplica; se vê e revê a si mesma e suas infinitudes. Este personagem criado pela fotógrafa traz as duas cisões identitárias. 
Vivian Maier produz uma outra ou outras de si que sai ou saem da sua superfície de linguagem. A fotografia se apresenta como espaço de virtualidade, a ilusão de realidade, imagens que procuram revelar as entranhas de sujeitos em seus obscuros conflitos, buscando o lugar e o sentido de estar no mundo, suas pluralidades, ela exibindo as indefinições de si mesma.

Seu autorretrato consiste nem uma demonstração de como ela constrói sua obra fotográfica e, ao mesmo tempo, sua autoimagem, em um jogo de representação que questiona o próprio ato de representar. $\mathrm{O}$ retrato que se traça ou autorretrato que se busca é a própria afirmação de que se vive na ficção, para além do real. A mise en abyme, na fotografia de Vivian Maier, uma inscrição de uma micronarrativa noutra englobante, traz os aspectos psicológicos da fotógrafa e os elementos artísticos que caracterizam sua obra, e, por sua vez, sua estética também revela os confrontos de identidade que ela traz consigo.

Seus autorretratos vivem o eterno retorno de seu fantasma, dado o jogo teatral da transferência, em que se projeta na reflexividade sem fim, espelha seu esfacelamento em sucessivas representações, no jogo visível nas fragmentações dos retratos para encontrar-se no abismo, entrecruzamento virtual de todas as suas imagens. Seus fragmentos, refletindo-se sobre espelhos multifacetados, produzem outras imagens dela mesma, que se desdobram e se multiplicam em fragmentos e partes esfaceladas.

Entre a ficção e realidade, entre a fotógrafa e a babá, Vivian Maier se entrega ao espectador tal qual o faz, não sem ironia, Roland Barthes ao se anunciar logo na abertura de sua autobiografia, Roland Barthes por Roland Barthes: "como um personagem de romance", uma ficção fabricada pelo próprio autor. No caso da fotógrafa-babá, seus autorretratos estabelecem um interessante jogo discursivo e sutil dos eus que se formam no jogo especular de espelho e lente da objetiva, que coloca o eu do sujeito representado em suspensão, ao não se deixar fixar numa única representação, mas sempre se abrindo às suas contradições na tentativa de desdobrar seus múltiplos e possíveis eus.

Retomando nossa pergunta inicial, sobre o que quer sugerir Maier ao se colocar em abismo em meio às estruturas do cenário escolhido, acreditamos que tais escolhas revelam o seu percurso artístico na fotografia, onde ela brinca com sua (s) identidade (s), seu (s) eu (s), conventendo-a (s) em objeto (s) que compõem a cena. Por meio de seu autorretrato, ela nos convida a vivenciar esses seus desdobramentos, a nos perdermos no seu mis em abyme. 


\section{Referências}

BARTHES, Roland. A câmara clara: nota sobre a fotografia. Trad. Júlio Castañon Guimarães. [ed. Especial]. Coleção 50 anos. Rio de Janeiro: Nova Fronteira, 2015.

BROWN, Camilla E. Identidade. In: HACKING, Juliet (edição). Tudo sobre fotografia. Trad. Fernanda Abreu, Fabiano Moraes e Ivo Korytowski. Sextante: Rio de janeiro, 2012.

CALVET. Louis-Jean. Roland Barthes - uma biografia. Tradução de Maria Angela V. Da Costa. São Paulo: Sciliano, 1993.

ENTLER, Ronaldo. Para reler A Câmara Clara. Revista FACOM. $N^{\circ} 16,2^{\circ}$ semestre de 2006. São $\quad$ Paulo. Disponível em <www.faap.br/revista faap/revista facom/facom 16/ronaldo.pdf >. Acesso em 10 de março de 2016.

GAILLARD, Françoise. Já i un três mauvais rapport à mon image. In: La Recherche Photographique. Maison Européene de la photographie, $\mathrm{n}^{\circ} 12$. Roland Barthes et la photographie, Paris Audiovisuel, 1992.

HIGGINS, Jackie. Fotografia urbana. In: HACKING, Juliet (edição). Tudo sobre fotografia. Trad. Fernanda Abreu, Fabiano Moraes e Ivo Korytowski. Sextante: Rio de janeiro, 2012.

LEDERMAN, Erika. Fotografia de rua. In: HACKING, Juliet (edição). Tudo sobre fotografia. Trad. Fernanda Abreu, Fabiano Moraes e Ivo Korytowski. Sextante: Rio de janeiro, 2012.

MACHADO, Arlindo. A ilusão especular: uma teoria da fotografia. São Paulo: Gtavo Gili, 2015.

MALOOF, John (coordenação). Vivian Maier: uma fotógrafa de rua. São Paulo: Autêntica, 2014.

\section{Documentário}

FINDING Vivian Maier. Direção de Charlie Siskel e John Mallof. EUA: 2013. 1:35:26. Disponível em http://www.megafilmesxhd.net/a-fotografia-oculta-de-vivian-maier/. Acesso em 13 de junho de 2016.

\section{Fotografias}

Site oficial sobre Vivian Maier. Disponível em: http://www.vivianmaier.com/gallery/self-portraits/\#slide-40. Acesso em 10 de maio de 2016. 